\title{
Expectation Changes and Team Characteristics in a Participatory Design Process
}

\author{
Conne Mara Bazley ${ }^{\mathrm{a},{ }^{*}}$, Annelise De Jong ${ }^{\mathrm{b}}$, Peter Vink ${ }^{\mathrm{b}}$ \\ a JimConna Inc., 5966 County Road 109, Carbondale, CO, 81623, USA \\ ' Industrial Design, TU Delft, Landbergstraat15, 2628 CE Delft, The Netherlands
}

\begin{abstract}
A human factors specialist researched the expectations of a culturally and professionally diverse team throughout a year long participatory design process of a large processing facility. For a deeper understanding of high-level team expectations and characteristics, the specialist collected data and information through in-situ ethnography and traditional case study methods, personal interviews, and a questionnaire that included a likert scale rating for expectation levels. Results found that expectation levels rated extremely satisfied for individual team members and the overall team itself before and during the participatory process. In contrast, expectations for upper management from the team were satisfied before the participatory process, but changed to uncertain, to unsatisfied, to extremely unsatisfied during the process. Additionally, the participatory design team exhibited high-level team characteristics to include honesty, competence, commitment, communication, creativity, and clear expectations
\end{abstract}

Keywords: Expectations, Team Characteristics, Participatory Design Process, Control Room Design, Diversity

\section{Introduction}

A human factors team attempted to review the completed designs for all control rooms in a large reprocessing facility. After realizing previous control room designs were incorrect, a human factor specialist formed a small professionally and culturally diverse design team to produce new control room designs. The participatory design process and research discussed in this paper span one year and discuss the expectation changes and high-level team characteristics exhibited by a small design team.

In the workplace, human factors specialists and ethnographers have similarities. Both disciplines use a form of observation of the process of work, the behavior of human beings interaction with each other, the work culture, the environment, time and space and are often times translators between engineers, designers and upper management. Additionally both are likely to be a part of a work team or participant of the group or team in a study [10].

\subsection{Participatory Design}

Participatory design is often used within smaller projects to generate prototypes that feed into an overall project's design process [6].This paper focuses on a larger project. By participating and observing the design process, the researcher determined whether expectation changes occurred during the process. Participatory design does not just ask users' opinions on design issues, but actively involves them in the design and decision-making processes [13]. Steen, et al., [14] state that "in participatory design end-users articulate a problem in their current situation and researchers/designers try to solve that problem together with them. In ethnographic fieldwork, the researcher/designer shifts towards the end-users by interviewing and observing them in their current work situation. Both aim to get insight in a current situation of end-users or to solve a current problem for them."

\footnotetext{
* Corresponding author. E-mail and Phone number: cbazley@jimconna.com, +1-970-618-5895.
} 


\subsection{Expectations}

Osvath and Osvath [12] conclude expectations in humans as "planning for future needs that relies heavily on two capacities, both of which lie at the heart of our cognition; and self-control. Often defined as the suppression of immediate drives in favor of delayed rewards, and mental time travel, which could be described as a detached mental experience of a past or future event. Future planning is linked to additional high complexity cognition such as metacognition and a consciousness."

Expectation can be defined as a belief about (or mental picture of) the future, anticipating with confidence of fulfillment, or the feeling something is about to happen [3]. One of the characteristics of team performance is expectation. Team members come to a team with their own past experiences and what is expected from them, as well as what they themselves expect from the team they are joining [11]

\subsection{Teams}

Forming multicultural teams is becoming more common as companies become more global. Janssens and Brett [9] wrote, "Collaborations are generally organized in the integration and/or the identity model or the coalition model. Dominant coalition sets the scene, overrides differences that are not in line with its logic, revise and suppresses other perspectives. This, in turn, creates a less culturally intelligent team model because it discourages meaningful participation in information extraction and decision making." The most common alternative approach, the integration and/or identity model, requires all team members to sublimate their cultural identities to that of the entire team by adopting "super ordinate goals" based on their common interests. The approach has the advantage of encouraging every team member to participate. However, it carries two risks. In the interest of unity, team members might submerge their cultural identities, and hence their ability to think differently. In addition, the effort to include everyone in decision-making might cause the team to function at the level of its least-creative member [9]. The fusion concept aims to overcome that type of problem by ensuring that every member contributes his or her expertise to the team's discussions. This takes careful organization and team management as every member contributes.
According to Douglas [5] successful teams have five things in place and a set of common characteristics i.e., (1) clear sense of purpose, (2) well understood norms of behavior, (3) measurable success indicators, (4) clear roles and responsibilities and (5) operating rules.

Additionally, successful high-level performance teams adopt a set of positive behaviors that include, dynamism, flexibility, action focus, and new challenge acceptance. Team attention directs itself towards capitalization based on competencies, high mutual trust, unconditioned team attachment, innovation, continuous learning and development. High performance teams respond to change and initiate it [1]. Horwitz and Horwitz [8]suggest that teams with denser expressive and instrumental social networks tend to perform better and remain more viable. These effects are especially potent when the network structures precede initial bouts of performance, but they diminish as time elapses and the familiarity between team members grows.

In this study, the definition of expectations are examined and measured by a likert scale for changes in expectations during the participatory design process and high-level team characteristics are observed and recorded through interviews and a questionnaire during the participatory design process

\subsection{Research Questions:}

1. How do expectations of the design team members evolve during the participatory design process and what factors influence the change in expectations?

2. Does the team exhibit high-level characteristics that make teamwork successful?

\section{Method}

The process presented here explores the high-level team characteristics and expectations of the small team as reported by the human factor specialist who was also a team member who gathered data by insitu ethnography and traditional case study methods as well as personal interviews, and a questionnaire. The ethnography entailed detailed observations and records of design meetings and outings to examine expectation levels and high-level team behavior and characteristics. For this study, a questionnaire and personal interviews were used to collect data and expectation levels were rated from 1-5 with 1 being extremely satisfied to 5 being extremely dissatisfied. 


\subsection{The Design Process}

The design process for the control rooms began over ten years ago and prior to the formation of the small design team discussed in this paper a team of two human factors engineering specialists were to complete reviews for the control rooms in the new facility. They created a guideline to provide a simplified design process for those reviews. The design of a new facility, based on an already existing process, layouts (including control room design) were to replicate the reference facilities located in a foreign country.

Preliminary layout designs and equipment lists were incomplete for all the new control rooms due to differences in standards and regulations from the reference facilities to the new facility. The human factors engineering group was assigned to redesign all of the control rooms as well as conduct the final review. The control rooms involve the entire facility and inclusion of other departments and facility groups i.e., nuclear safety, operations, chemical engineering, manufacturing and laboratory system engineers, procurement...etc. was necessary to gather needed information about equipment and other control room needs. HFE held several large meetings over a year with many representatives from other departments to discuss the new layout designs. After several of the large meetings, it was apparent that the formation of a smaller layout participatory design team was necessary to complete the control room layouts. The smaller design team distributed the knowledge gathered from their own design meetings to the large groups through email once a week or by invitation to large group meetings that were scheduled quarterly or as needed depending on what major issues ensued.

\subsection{The Design Team}

To work effectively in a culturally diversified team requires listening, open mindedness to different perspectives of critical thinking and problem solving techniques. Additionally, it is important to accept that the parties at the table come with a unique frame of reference, lessons learned, and preconceived expectations [9]. The small design team met once a week for over a year. The team sent new layout information for review and comments to the larger groups either by email or by bi-monthly meetings for discussion and confirmation for final layout design.
The organizer, and data collector was a human factors specialist and applied psychologist, from the western USA, who facilitated and participated with a small design team:

- $\quad$ Team Member (1) A senior instrument and control and software engineer, with years of corporate, government, and military working experience, from Britain;

Team Member (2) A software engineer from France from one of the reference plant facilities, very detailed oriented and wore two hats; one for operations and the other for software design,

- Team Member (3) A chemical engineer from operations with years of operations experience who was intense and dramatic, from the south-eastern USA; and

Team Member (4) An electrical designer, excellent technical skills, pays particular attention to what goes on "outside the box", from the south-eastern USA.

Team members preferred to visit the structure while under construction in addition to working on model layouts. The experience of being in an actual room helped with special determinations and the future physical control room environment. During outings and meeting times the team often referred to the overall project as the "French Castle" or "French Fortress" due to the massive scale and extreme thickness of the double walls filled with debris surrounding the inner core structure (Figure 1.).

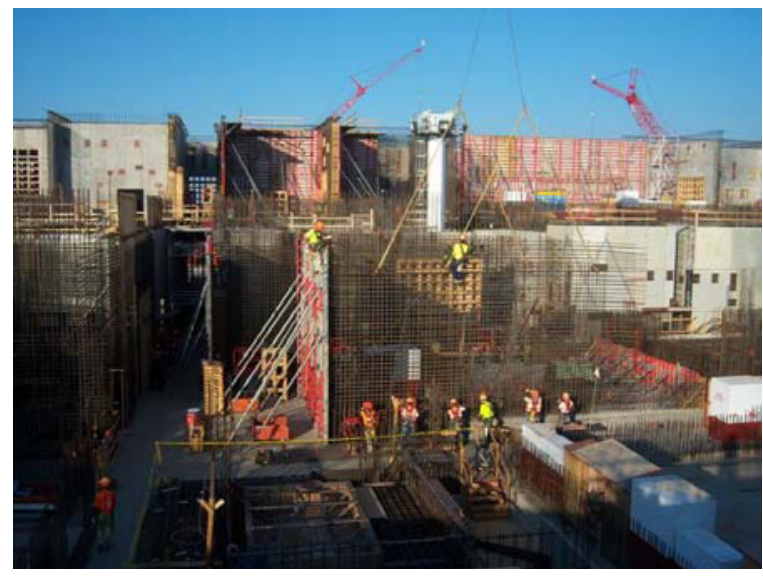

Figure 1. The new facility walls and levels $\mathrm{n}$ full construction phase.

Due to the $20 \%$ reduction in the building footprint from the original design and added extra amount of equipment and piping needed to comply with the new standards and regulations, the team speculated 
on what type of control room operators might fit and work in the cramped, low-ceiling labyrinth environment.

\subsection{The Questionnaire}

The questionnaire contains ten main questions. The questionnaire was given before and during the design process. The first six questions asked the team members about the participatory process and discussed in detail during the interviews. The next four questions ask for comments, and a yes and no answer, and the last two questions are rating scales on expectation levels.

The team was asked to rate the outcome of their expectation levels before and during the participatory design process (a) for themselves as a team member, (b) their own expectation for the small team as a whole, and (c) the expectations they had for upper management. A likert rating scale was used from $1-5$, with 1 being extremely satisfied and 5 being extremely dissatisfied, Some examples of the questions asked: What were the main expectations from the control room project for you and were your expectations met? What expectations did upper management have for team performance? Were upper managements expectations met? Other questions asked about the design process were covered during the interviewing sessions but are not the focus of this paper.

\section{Results}

For this study, the expectations from the team members included the explicit sharing of the quality and project completion values: goal, visions and objectives from the part of all team members. Strong focus on results, the sense of priorities, and clarity in decision were also fundamental for the team to meet high performance standards. However, the team was extremely dissatisfied with the expectations for upper management and other groups in terms of communication and rated them very unsatisfied on the expectation scale.

\subsection{Expectations}

During the participatory process experience, the team began to share their expectations for the assignment.
Team member (2), "I tried to share my knowledge of the French control rooms processes" or

Team member (3), "The expectations of the TEAM are the SAME as my own" and

Team member (1), "team member 3 is forceful and knows (usually) what she wants but can be told differently. Myself and team member 2 both know what we're talking about and don't appear to be too stuck on any position. Team member 4 does a fantastic job interpreting what we decide. The human factors specialist is a good organizer / coordinator that get the meetings to happen and drag us back on track etc.

The ratings for themselves as team members before and during the design process were all 1's, 1 being extremely satisfied, and for the small team they were also all 1's. Despite challenges and compromises, the team rated their expectations as extremely satisfied for themselves and for the small team. The expectations did not change during the participatory design process. Team member (4) said, "Each step was exciting - Eager, to make this design and project one to be proud of and able to use as a presentation if necessary to the client. This was a virgin control room for this project and so therefore there were no roots to follow as far as numbering, sizing, baseline furniture, steps or procedures to follow or milestones to track."

However, expectation ratings for upper management did change and were mixed before the design process with several 4's, (4 being dissatisfied), and several 5's, (5 being extremely dissatisfied) Expectations for upper management during the design process scored a 5 for all team members, (5-expremely dissatisfied). Upper management did not appear to be interested in control room layouts and did not express satisfaction or dissatisfaction with the team. The team viewed this as disinterest and lack of communication that existed in previous lower level design efforts in this overall project.

Team member (3) said, "I don't know if upper management expectations for the team were met. I know upper management did not meet team expectations, not good communication with the Team." Team member (1) said, "I think the overall project and upper management had this expectation for some sexy, futuristic wall mounted large screen monitors that telepathically display whatever the operator desires. Therefore, if that is what they expected, their expectations were not met; on the other hand, if they expected a complete design, than yes, expectations were met. Upper Management was missing in action. If they cared they would have pushed some of the 
other groups into actually doing some work." Team member (3) said, "Upper management's main interest was to finalize the design. Some (upper management) did not care if it was right or not, but just to finalize it. The good news is that the (small design layout) team made sure it was correct." Team member (4) responded, "Pushing out the project in unreasonable time, the time constraints were not measured in dates, but measured in the dates given with the time allowed to spend on project per day or week."

Along with the expectations of upper management, additional expectations were apparent from other project groups (those involved in the larger review meeting). Issues and frustrations with other groups and expectations from the small group for the larger group and vice versa were expressed although not rated but voiced during the interviews:

Team member (1) said, "Dealing with the "human factor' aspects, OK a console uses up so much space and you have to decide where to put it. Explaining this to an annoying human in a large groups meeting though will just keep on wasting time blah, blah, blah. You know, everybody has met these folks! Two frustrating things really: firstly getting the stuff to fit in the space allocated and secondly the human problems: getting the individual disciplines to come up with their requirements. Luckily the second one got solved by drastically cutting down the number of individuals who really worked on the layouts (and this cut out those who liked to ramble on, distract the meeting, just complained etc. etc.)."

Team member (3), "It was definitely a negotiation with other larger groups."

Team member (4), "Groups who don't know what they want or need in the control room, as if we can wait until later on when they make their minds up to get their stuff in there and we are expected to integrate changes with incomplete or inaccurate inputs (from other groups). The team made the best decisions at the time for the problems that were at hand. The team did not foresee the objections later in the project by others, and the team made all efforts and changes to abide by their new policies (for lack of a better term)."

\subsection{Team Characteristics}

When finished, the reprocessing facility building will be windowless, concrete, gray, cold, and mammoth. The missing effects: are the drawbridge, a moat (filled with the local alligators) and the roofline adorned with security guard gargoyles spurting fire, hot oil or gushing water after a momentous rainstorm.

The team often used narrative and communicative behavior on their outings and in their meetings. According to Herman [7], "stories help organize the turn-taking behavior of the parties engaged in narrative communication and narrative is a means of redressing problems that arise when anticipated similar experiences do not materialize. Stories can be told prior to or in the absence of any real failure of expectation, in order to question the explanatory limits of expectation-inducing and - sustaining typifications."

Finding adequate space for equipment and workstations were and continue to be the biggest challenges to this project from the standpoint of design. The realization and response to space constraints was expressed by team member (1) during a personal interview said "Initially, there was all this moaning about how little space we had and this seemed overdone, however by starting to shove stuff in the first control room and the way that more and more stuff kept appearing. Then seeing the actual space that is allocated for the first control room (obviously which was seen on drawings) but the reality of just how low the ceiling is etc. made me into a true "believer" to keep stuff out of the control rooms.

Additionally, providing adequate, comfortable workstations for a large number of operators was hampered by space constraints.

The following is an example of team frustration paired with team creativity. The design team did not have a designated designer assigned specifically to the control rooms and the need to work on a preliminary layout continued without a designer. Team member (1) and the human factors specialist came up with the idea to cut out colored pieces of paper for workstations (Figure 1). Team member (1) brought the to-scale cut out pieces of papers to represent workstations to a team meeting. The team members worked together and fitted the cut outs on the preliminary drawing in the correct process order. During the creation time each member filled in the gaps, discussed workstation placement and work flow and what needed to be near each other and why. The meeting time was calm, easy, and fun.

There were no arguments, just a lot of laughter. Hence, images of vampire penguins (hybrid) who were short and small, able to fit at the undersized workstations, withstand the cold, able to see in the dark, have wings, can fly, able squeeze in and out of tight spaces and walk through walls. Sleeping accommodations and ways to feed the hybrids were discussed. Flying monkeys were also considered 
because they have tails and could hang off the pipes to perform maintenance duties in hard to reach spaces.

Herman [7] discusses narrative representatives behavior where, "stories can be used to engage in "problemraising,"i.e., to throw into relief ways in which situations and event depart from the typical or the expected. On the other hand, received stories about the world provide a context of typicality in terms of which unexpected occurrences can be interpreted, enabling various modes of problem-solving." Team member (4) finally said, "This is a billion dollar project and we are using tape, colored paper, a ruler, and markers to design a control room for operators to work in for twenty years. This is not normal, is it? "In reality, this is a common way to do design according to conversations with design professionals. The humor was a redeeming quality in an often times depressing and oppressive environment of conceptual design mishaps and constant design changes. Upper management was obsessed with the concrete and construction schedule and was not amenable to necessary design changes, although those changes are inevitable. The team was very professional and strived for perfection in the layout designs.

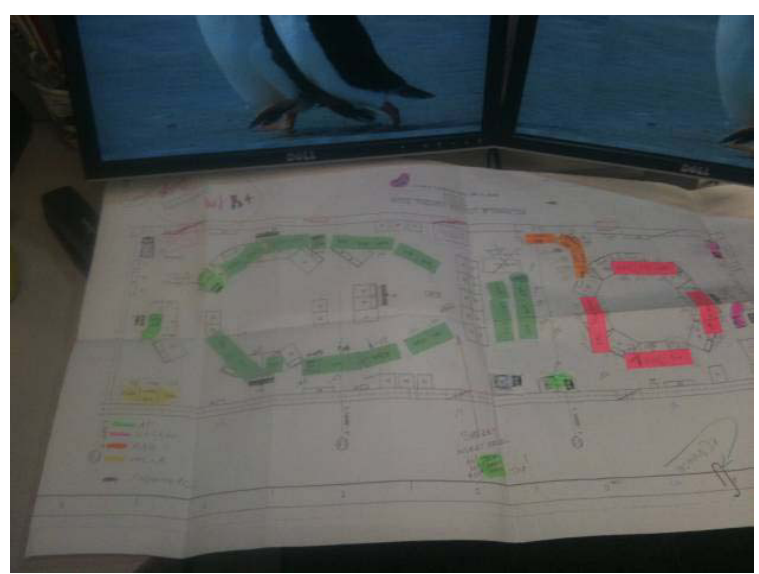

Figure 2. Showing the use of colored paper for workstation design.

\subsection{High Level Team Characteristics}

The high-level team discussed in this paper adopted the fusion concept. Additionally, the team did not have a leader hence the fusion team style ensured an equal input of expertise from all members. The human factors specialist organized and facilitated all meetings and the gatherings, but each member contributed equally [9]. To counter act dimin- ished effectiveness, this case study suggested introducing new players to the team intermittently, especially when expertise is required from lead engineers or those individuals familiar with the reference plant operations and processes.

\section{Discussion}

Not unlike comfort levels, expectations are subject to interpretation. The English language complicates it even more by using the word in different contexts [3]. That said the study did ask that each team member rate his or her own expectation level, the level of the team as a whole, and the expectations upper management had for the team as a whole.

The team felt that upper management was not interested in the design process of the control rooms. Upper management had the appearance of a quasi Laissez-faire leadership style where the leader's role is peripheral and the teams manage their own areas of the business; the leader therefore evades the duties of management and uncoordinated delegation occurs. The communication in this style is horizontal, meaning that it is equal in both directions, however very little communication occurs in comparison with other styles. The style brings out the best in highly professional and creative groups of employees, however in this project, being creative was not encouraged and not all managers had the same style. This style of management often leads to a lack of staff focus and sense of direction, which in turn leads to much dissatisfaction, and a leads to a poor company image [5].

Team members noticed a lack of communication with and from upper management and voiced strongly that upper management's main concern was a construction schedule deadline. The team originally envisioned and expected state of the art control room designs. They were disillusioned and distressed by the lack of interest from upper management. Upper management tended to isolate groups from each other making communication difficult. This was the preferred upper management style and caused design issues for the team because the control room layout involved the "big picture" to include all stakeholders in the layout designs. These types of problems typically stemmed from the top.

Ideally, in order to assist teams with change, leaders themselves present a positive attitude and help teams envision the opportunities. Change leaders may ensure the necessary safety for teams willing to 
take risk, as well as the necessary instruments to have teams innovate necessary change High performance teams have not only to respond to change, but also initiate it [1].

Janssens and Brett [9] found that managers often set up their teams to fail because they themselves fail to help the team anticipate changes or communicate the changes in a timely fashion. Two of the basic elements of fusion are meaningful participation and coexistence. The team was expected to provide innovative solutions to problems. Figure 3 shows an example of the original conceptual design before the team began the new layout designs. Figure 4 shows the final design after numerous design meetings, outings and discussions.

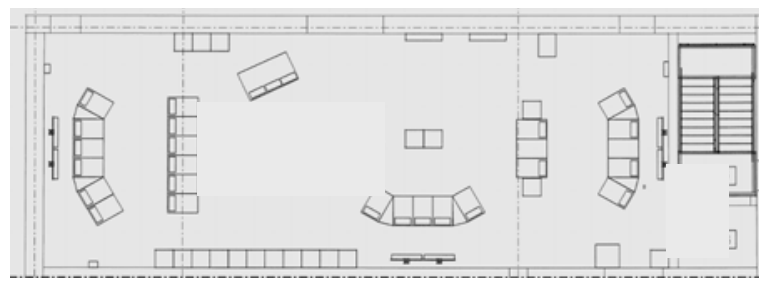

Figure 3: Control Room layout in conceptual design phase.

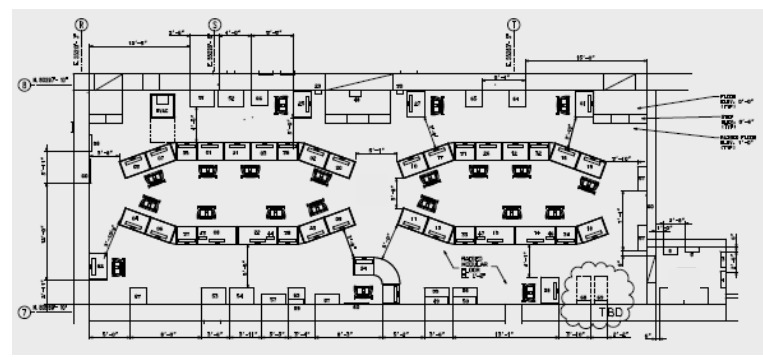

Figure 4: Control Room layout in final design phase.

Although the team was multicultural, cultural differences did not interfere with the expectations or participatory process. Multicultural differences were not a hindrance but beneficial due to the international nature of the project design. The team appreciated the differences and thereby enhanced the process by the sharing of diverse perspectives on problems and creative solutions. The team enjoyed the humor of team member (1) and looked forward to the meetings and outings because they expected to have a good time together, albeit frustrating at times. Creative solutions to the problems often came out of a heated discussion or funny comment and the team would regroup and be ready to move forward and not bog down with drama or useless drivel.
Deuutsch [4] considered the effects of cooperation versus competition on group performance. He found two important practical implications of the results of his study: (1) greater group productivity results when the members are co-operative rather than competitive in their interrelationships; (2) competitiveness produces greater personal insecurity (expectations of hostility from others) than does cooperation.

The team exhibited the following qualities of a successful team. Being honest with themselves and others involved in the design process through frank dialog and providing professionalism, expertise and competence in presenting those aspects in wellthought out control room designs. The team expressed an overall commitment to the project through frustration, collaboration, innovation and creativity, clear expectations from themselves, expectations for other team members and those for upper management, and communicated clearly and concisely the needs of the team as often as possible and forwarding their results to other groups and stakeholders throughout the layout design process.

\section{Conclusion}

The participatory design process resulted in a successful high level, multicultural design team. Team factors included honesty, competence, commitment, communication creativity, clear expectations and moderately happy consensus with layouts considering project challenges. The team was collaborative, determined, strived for perfection and worked diligently to create control room layouts for the health and safety of future facility operators. The team demonstrated the characteristics of a successful team according to Douglas [5] and Abrudan and Brancu [1].

\subsection{Expectations}

Expectation levels were extremely satisfied for individual team members and the overall team itself, at the beginning and during the design process. Expectations from the team for upper management at the beginning were dissatisfied, although during the design process the expectations became less certain and rated extremely dissatisfied. The extremely dissatisfied ratings may have been largely attributed to management agendas and priorities i.e., Concrete pour 
schedule, unrealistic due dates, different management styles, and major attrition in upper management and general employment personnel that occurred throughout the design process.

\subsection{Team Characteristics}

Challenges prompted responses from team members and required innovation honesty and collaboration to formulate viable solutions as demonstrated by the revised control room designs.

The team exhibited a clear understanding of what each individual expects from themselves and the team as a whole and a commitment to being part of a team but still reflecting their own characteristics. It showed competence and the strength of the team as directly proportional to its members' abilities and initiative, clear and honest communication with each other, cooperation and efficiently working together, and creativity and innovative spirit and open to new ideas and initiating change.

The aforementioned characteristics are key aspects in a high-level team.

Communication deficiencies with upper management and others leads in the larger groups were and continue to be the most challenging to the team expectation levels and progress in the layout design process overall. Managers are attuned to hear findings directly from technical experts, the systems developers, customer account managers, market analysts, and computer scientists we work with may contribute substantially to a change of attitude in the company [10]. This is also true with human factor specialists who are included in multicultural teams with professionals from different disciplines. Individuals from all disciplines can demonstrate the importance and benefits of human factors to the success of the project

\subsection{Participatory Design}

According to Chapanis [2], "human factors is a body of knowledge about human abilities, human limitations, and other human characteristics that are relevant to design. Human factors engineering is the application of human factors information to the design of tools, machines, systems, tasks, jobs, and environments for safe, comfortable, and effective human use".
During the layout process, the team realized the importance of including the 'human factor' into the layout designs. Team member (1), "This process has really put in perspective, for me, the importance of the 'human factor' aspects." Team member (2), "I learnt a lot about the 'human factors' issues." Team member (3), "We were pushed for space so 'human factors' became a big player in this part of the project." Team member (4), "How we can maximize space in the control room including incorporating 'human factors' elements into the design?"

Participatory design team opportunities provide for the inclusion of both human factors and ethnography in present and future design and system development work. Additionally, the inclusion of ethnography in the usability methods for this study and future projects prove beneficial as a complimentary evaluation technique for a deeper understanding of diverse team expectations, team behavior and work culture throughout a participatory design process.

\section{Acknowledgements}

This project would not have been possible without the insights, input, innovations, humor and support of the Control Room Design Layout Team. Thank you.

\section{References}

[1] D. Abrudan, L. Brancu, Solution in Crisis Period - High Performance. Team Review of International Comparative Management. 10(2) (2009) 457-460.

[2] A. Chapanis, To Communicate the Human Factors Message, You Have to Know What the Message Is and How to Communicate It, Human Factors Society Bulletin, 34 (11) (1991) 1-4.

[3] Collins English Dictionary. HarperCollins Publishers Ltd. Dictionary database indexing and processing provided by UltralinguaInc. (C) 2010 http://www.collinslanguage.com.Retrieved from internet May 1, 2009.

[4] M. Deutsch, An experimental study of the effects of co-operation and competition upon group process. Human Relations 2 (1949) 199-231. 
[5] E.Douglas,

http://www.articlesbase.com/smoarticles/five-elements-of-effective-teams1581266.html\#ixzz15a1OXUgI.Retrieved from internet, May13, 2009.

[6] T.Fidgeon, http://www.webcredible.co.uk/userfriendly-resources/web-usability/usercentered-design.shtml. Retrieved from internet, May1, 2009.

[7] D. Herman, How tories Make Us Smarter. Recherches en communication, $\mathrm{n}^{\circ} 19$ (2003) 8-9.

[8] S. Horwitz, H. Horwitz, The Effects of Team Diversity on Team Outcomes: A Meta-Analytic Review of Team Demography. Journal of Management 12 (33) (2007) 9871015.

[9] Janssens, M., Brett J. (2006). Cultural Intelligence in global teams: A fusion model of collaboration, Groups \& Organization Management, 31 (1), (2006) 124-150.
[10] B Jordan, B Dalal, Persuasive Encounters: Ethnography in the Corporation. Field Methods, 18 (4) (2006) 1-24.

[11] J. Katzenbach, D. Smith, The Disciplines of Teams.Harvrad Business Review, 3(4) (1993) 118-119.

[12] M. Osvath, H. Osvath, Chimpanzee (Pan troglodytes) and orangutan (Pongo abelii) forethought: self-control and pre-experience in the face of future tool use. Animal Cognition Journal, Springer Berlin / Heidelberg (Online) 11 (4) (2008) 1435-9456.

[13] Schuler, Douglas and Aki Namioka Participatory Design: Principles and Practices. New Jersey: Lawrence Erlbaum Associates. (1993),

[14] M. Steen, L. Kuijt-Evers, J. Klok, Early user involvement in research and design projects $-\mathrm{A}$ review of methods and practices Paper for the 23rd EGOS Colloquium (European Group for Organizational Studies) July 5-7, Vienna. (2007) 